\title{
"I can almost taste it:" Why people with strong positive emotions experience higher levels of food craving, salivation and eating intentions
}

\author{
David J. Moore $^{\mathrm{a}, *}$, Sara Konrath ${ }^{\mathrm{a}, \mathrm{b}, \mathrm{c}}$ \\ ${ }^{\text {a }}$ University of Michigan, USA \\ ${ }^{\mathrm{b}}$ University of Michigan Institute for Social Research, USA \\ ${ }^{\mathrm{c}}$ University of Rochester Medical Center, USA
}

Received 20 January 2012; received in revised form 2 July 2014; accepted 8 July 2014

Available online 15 July 2014

\begin{abstract}
The goal of this paper is to examine whether individual differences in affect intensity predict people's responses to food advertisements. In doing so, we aim to uncover individual differences and situational factors that are associated with higher food cravings and other consumptionrelated responses. Studies 1 and 2 identified three mediators (emotional memories, weak impulse control, and the intensity of pleasure anticipation) which indirectly link affect intensity to food cravings and behavioral intentions. Studies 3 and 4 identified two moderators (vividness of advertisement, dieting status of participants) of the relationship between affect intensity and consumption-related outcomes. In Study 3 high affect intensity individuals reported stronger food cravings only in response to vivid advertising appeals. In Study 4, respondents with high levels of positive affectivity, a sub-dimension of affect intensity, experienced increased salivation, but especially when they were dieters exposed to vivid food images. Implications for theory development and for marketing and public policy strategists are discussed.

(C) 2014 Society for Consumer Psychology. Published by Elsevier Inc. All rights reserved.
\end{abstract}

Keywords: Affect intensity; Positive affectivity; Emotional memories; Pleasure anticipation; Food cravings; Salivation

\section{Introduction}

Most consumers can recall some occasion when they experienced cravings and salivation for tempting foods like a hot delicious pizza loaded with appetizing toppings and thick sizzling mozzarella cheese oozing over the edge. These cravings may have been activated by exposure to vivid food advertisements, or enticing aromas when walking past a restaurant. Food cravings are cue-elicited expectations that are stimulated by the anticipation of food-related sensory pleasures (e.g. sweetness, texture, aroma; Cepeda-Benito, Gleaves, Williams, \& Erath, 2000). Cravings go beyond liking or preferring a type of food.

\footnotetext{
* Corresponding author at: Department of Sport Management, University of Michigan, 1402 Washington Heights, Ann Arbor, MI 48109, USA. Fax: +1 7346472808 .

E-mail address: djmoore@umich.edu (D.J. Moore).
}

Rather, cravings are intense feelings of appetitive desire that are vivid, overpowering, and feel uncontrollable (Belk, Ger, \& Askegaard, 2003; Loewenstein, 1996), often with a focus on a specific food item (Belk et al., 2003; Fedoroff, Polivy, \& Herman, 2003; Pelchat, Johnson, Chan, Valdez, \& Ragland, 2004). They can collapse one's self-control and increase the likelihood of buying and consuming unhealthy food (Siwik \& Senf, 2006; Tice, Bratslavsky, \& Baumeister, 2001).

Food cravings have been linked to overeating and higher levels of fast food consumption, both of which may be contributing to the rise in obesity-related diseases (Siwik \& Senf, 2006). Obese individuals have $42 \%$ higher medical bills, and obesity itself is responsible for over $9 \%$ of all American healthcare spending (Stipp, 2011). Thus, uncontrolled food consumption brought on by cravings represents a serious economic and public health issue, thereby underscoring the importance of understanding the specific role of marketing and 
advertising in stimulating food craving. Furthermore, since cravings are powerful visceral drives that undermine the control of food intake by both dieters and non-dieters alike, we need more understanding about how consumers differ in their responses to vivid presentations of food cues. It is inappropriate to assume that consumers are homogenous in their reactions to marketing stimuli designed to stimulate food consumption.

This paper presents and tests a theoretical model designed to predict impulsive food consumption-related outcomes. In doing so, we aim to uncover individual differences and situational factors that are associated with higher food cravings and other consumption-related responses (Fig. 1). We follow a person by situation theoretical approach that has been successfully used to predict other impulsive behaviors (e.g. aggression: Anderson \& Bushman, 2002; sexual behaviors: Cooper, 2010). Thus, we apply the prevalent interactionist view within personality and social psychology to food consumption-related outcomes (e.g., cravings, behavioral intentions, and salivation), hypothesizing that these outcomes should depend on both individual differences (e.g. traits such as affect intensity, individual differences such as dieting status) and contextual factors (e.g. features of advertisements).

Fig. 1 gives an overview of the current studies, and we now briefly review the key research questions that they address. First, are there predictable individual differences in craving intensity after advertisement exposure? For example, people tend to differ in the intensity of the emotions ("affect") they experience when exposed to emotionally-charged stimuli (Larsen \& Diener, 1987; Moore, Harris, \& Chen, 1995). However, it is unknown whether affect intensity is related to craving intensity, behavioral intentions, and salivation responses. Understanding the role of affect intensity is important because of the possibility that people who are dispositionally inclined to experience their emotions intensely may be the same ones who have difficulty controlling their food cravings and appetitive impulses (Fedoroff et al., 2003; Hofmann, Friese, \& Strack, 2009).

Second, why should affect intensity be associated with more consumption-related outcomes? Can we uncover potential mediating variables that help to explain its role in eliciting cravings and other consumption-related responses? In Studies 1 and 2 we identify three psychological processes that help to explain why affect intensity may directly or indirectly stimulate food cravings: (a) the role of emotional memories; (b) the weakening of impulse control, and (c) the intensity of pleasure anticipation, all of which are hypothesized to amplify cravings in high affect intensity individuals (see Fig. 1).

Third, Studies 3 and 4 examine whether these relationships are moderated by vivid versus pallid product descriptions, and the dieting status of the respondent (Study 4). These moderated relationships should be investigated to better understand how appetitively charged advertising appeals affect a variety of consumers differently. Specifically, to what extent does the vividness of product descriptions in advertisements contribute to the stimulation of food cravings among high affect intensity people? Furthermore, does being on a diet also affect how these individuals respond to such vivid cues? Studies 3 and 4 also examine the importance of measuring salivation - a non-conscious physiological response in anticipation of the pleasure of food consumption (Krishna, Morrin, \& Sayin, 2014; Spence, 2011).

Fourth, are specific sub-dimensions of the affect intensity construct (Larsen \& Diener, 1987) more likely to impact consumption-related responses? In Studies 2 and 4, this paper makes important theoretical contributions by testing which of the sub-factors of the affect intensity construct, positive

\section{A) AFFECT INTENSTTY}

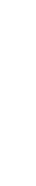

B) MEDIATOR S (Studies 1 and 2)

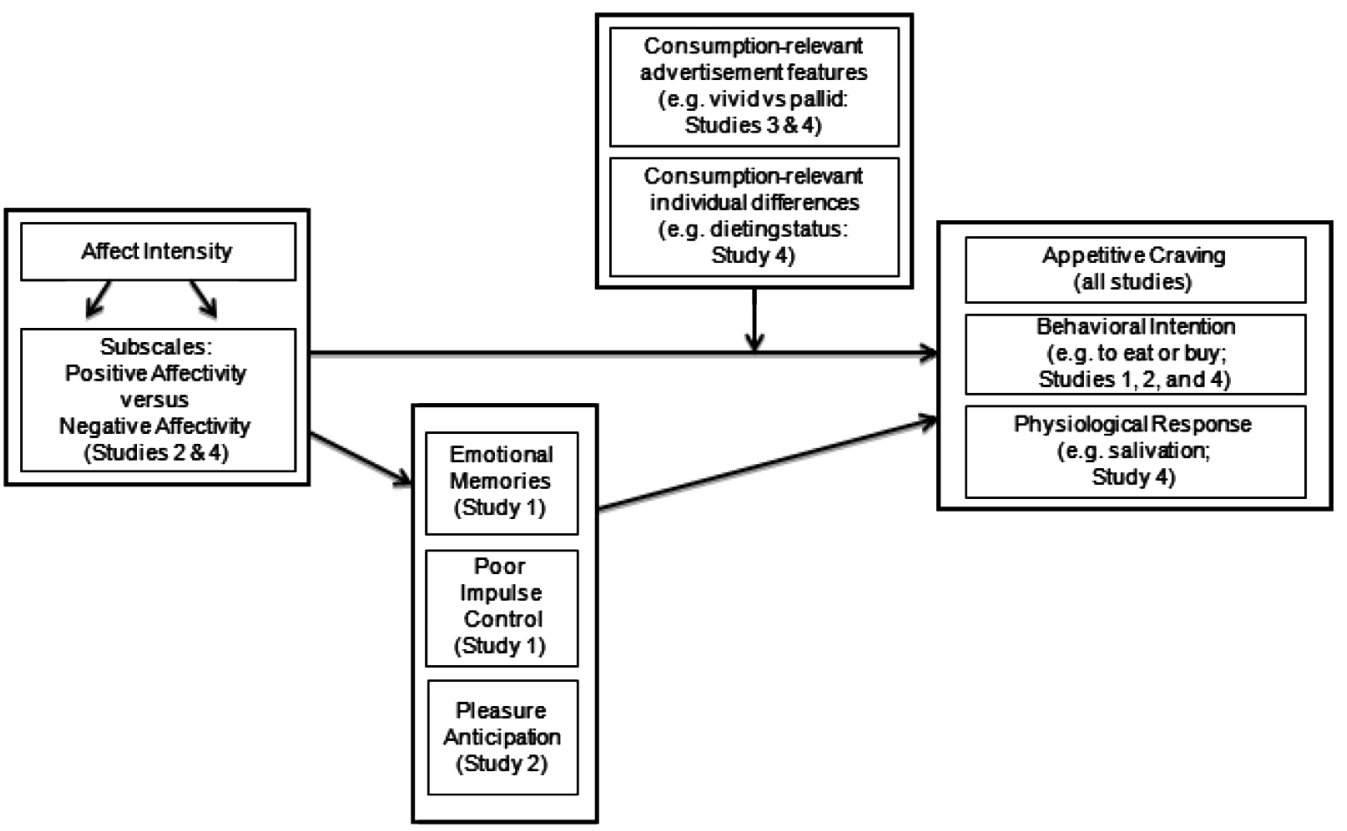

C) MODERATOR S

(Studies 3 and 4)

\section{D) OUTCOMES}


affectivity versus negative affectivity, is uniquely related to consumption-related outcomes (Bagozzi \& Moore, 2011; Bryant, Yarnold, \& Grimm, 1996). This is important because researchers have noted that when personality constructs are multidimensional (e.g., the affect intensity scale), the use of specific sub-dimensions of the scale may be more interpretable and less misleading than the use of the total scale (Bagozzi, 1994). More importantly, there is some level of ambiguity about the relative impact of positive affectivity versus negative affectivity in responses to vivid cues. For example, it is quite possible that when people experience negative feelings or moods (Gardner, Wansink, Kim, \& Park, 2014), they will indulge their immediate impulses to eat tasty snacks in order to restore positive feelings - the "if you feel bad, do it" syndrome (Fedorikhin \& Patrick, 2010; Garg, Wansink, \& Inman, 2007; Tice et al., 2001). Thus, negative affectivity may promote craving intensity. On the other hand, it is also possible that people with more positive feelings will be more strongly driven by positive anticipation, which may stimulate more intense cravings (Alba \& Williams, 2013). Therefore, both positive and negative affectivity may predict cravings, thus creating a potential theoretical conundrum that this paper can address. We start with a review of the literature associated with the model (Fig. 1).

\section{Literature review and hypotheses}

\section{Affect intensity and consumption-related outcomes}

Affect intensity is the tendency to experience the emotional world vividly and deeply (Larsen \& Diener, 1987). When people are exposed to emotionally charged stimuli, those with high affect intensity engage in mental elaborations that intensify their emotional reactions. For example they focus on their feelings and on emotionally evocative details of stimuli. They also engage in fantasy elaboration, by imagining and visualizing, for example, consumption experiences beyond the information provided by the stimuli. Presumably, fantasizing about the anticipated consumption experience may increase food cravings (Larsen \& Diener, 1987). High affect intensity people also exhibit high sensitivity to tactile, auditory, visual, and olfactory stimulation (Kergoat et al., 2012; Larsen, Billings, \& Cutler, 1996), reporting more enjoyment of sensory arousal experiences such as smelling the aroma of freshly baked bread and the fragrance of perfumes (Moore \& Homer, 2000). Thus, one might expect that they would also experience more cravings.

Affect intensity consists of six sub-factors (Bagozzi \& Moore, 2011). In this paper we focus on the two most relevant ones: positive affectivity and negative affectivity (Bryant et al., 1996). Positive affectivity is the degree to which individuals experience intense positive feelings (e.g. "When I feel happy, it is a strong type of exuberance"), versus negative affectivity, which is associated with unpleasant emotions (e.g. "Sad movies deeply touch me"). Positive affectivity may be more appropriate for identifying people who are focused on anticipating or seeking pleasurable experiences (Alba \& Williams, 2013;
Fedoroff et al., 2003). Thus, when possible (i.e. in Studies 2 and 4), we contrast the positive affectivity versus the negative affectivity dimensions in predicting the consumption-related outcomes.

\section{Appetitive cravings}

Food cravings are strong motivational states similar to visceral drives such as thirst, hunger, or sexual desire (Bagozzi, 1992; Hill, 2007). High affect intensity people (especially those with high positive affectivity) are more likely to seek out pleasurable experiences (e.g. tempting food), and seeking out these experiences encourages cravings (Belk et al., 2003; Pelchat et al., 2004). One possible reason is that positive affectivity represents a consistent temperament that seeks out positive experiences to achieve emotional arousal (Larsen et al., 1996; Moore \& Homer, 2000). Therefore, unlike those with high negative affectivity, high positive affectivity respondents are motivated to indulge in imagination and visualization of pleasure-producing consumption experiences that stimulate cravings (Hill, 2007).

\section{Behavioral intentions}

Emotionally charged stimuli (e.g., chocolate cake) may impinge on the affective system by evoking cravings (Fedoroff et al., 2003), which in turn activate consumption impulses (Loewenstein, 1996; Loewenstein \& O’Donoghue, 2007; Shiv \& Fedorikhin, 2002). These impulses can occur quite suddenly because they are not consciously or carefully planned (Bagozzi, 1992). However, once behavioral impulses are activated, they become very difficult to suppress because they encourage the pursuit of immediate gratification-seeking action tendencies (Hofmann et al., 2009; Metcalfe \& Mischel, 1999; Rook, 1987; Shiv \& Fedorikhin, 2002). Neuroscientists have shown that the sight or smell of tempting foods like chocolate cake can be transformed into powerful sensations of pleasure through a coordinated network of 'hedonic hotspots' in the brain (Berridge, Ho, Richard, \& DiFeliceantonio, 2010; Pecina, Smith, \& Berridge, 2006). Given the sensitivity of the affect intensity temperament to emotional stimuli (Larsen et al., 1996; Moore \& Homer, 2000), high affect intensity people (especially positive affectivity) are also likely to have stronger behavioral impulses and intentions than those with more negative affectivity (Bagozzi \& Moore, 2011; Bryant et al., 1996; Larsen et al., 1996).

\section{Positive affectivity and salivation}

Intense cravings can possibly lead to physiological reactions like salivation (Krishna et al., 2014; Spence, 2011). The human tongue is permanently covered with a saliva coating that is vital to food digestion and taste perception (Bonans \& Noble, 1995; Spence, 2011). Since salivation is a non-conscious response controlled by the autonomic nervous system (Winsor, 1930), it is possibly a more reliable measure of appetitive responses to food stimuli than self-reports alone (Pelchat et al., 2004). Several studies confirm that the sight or smell of palatable food 
is associated with increased salivation and a strong desire to eat (Klajner, Herman, Polivy, \& Chhabra, 2000; Krishna et al., 2014; Nederkoorn, Smulders, \& Jansen, 2000; Pangborn \& Berggren, 1973; Rogers \& Hill, 1989 - but see Spence, 2011, for null results).

In this paper, we are particularly interested in comparing the salivary responses of people who are associated with the positivity versus negativity sub-dimension of the affect intensity construct (Bagozzi \& Moore, 2011). Given the differences among people who may be classified with positive versus negative affectivity, it may be inaccurate to assume that people will always show homogeneous salivary responses to appetizing stimuli. Compared to their negative affectivity counterparts, positive affectivity people are more likely to engage in fantasizing about the pleasures of anticipated consumption experiences (Larsen et al., 1996), especially when exposed to vivid pictures of appetizing food (Ilangakoon \& Carpenter, 2011). We therefore predict that high positive affectivity people will show not only higher levels of food cravings and stronger behavioral intentions, but also more salivation (Krishna et al., 2014).

\section{Testing potential mediators}

Fig. 1 identifies three psychological pathways, or mediators (Studies $1 \& 2$ ) that may help to explain why affect intensity stimulates food cravings and behavioral intentions: (a) emotional memories; (b) poor impulse control, and (c) intense pleasure anticipation.

\section{Emotional memories}

The input of emotional memories may play a role in amplifying cravings among high affect intensity individuals (Hamann, 2001). In response to emotionally charged stimuli, high affect intensity individuals are more likely to focus on specific emotional details associated with memories (Larsen et al., 1996). These emotional memories are likely to be activated and enhanced by evocative memory cues. To illustrate: Cinnabon ${ }^{\mathrm{TM}}$ rolls are known for their distinctive aroma and pleasing taste. An advertisement referring to their aroma can serve as a memory cue that may stimulate cravings and behavioral intentions (Cepeda-Benito et al., 2000). Affective neuroscientists have shown that such memory cues can activate hedonic hotspots in specific brain regions and transform mere sensory inputs into pleasurable stimuli (Pecina et al., 2006; Smith, Mahler, Pecina, \& Berridge, 2010). For example, sweetness by itself is merely a sensation, but the neural systems associated with the hedonic hotspots make sweetness feel rewarding and pleasurable (Pecina et al., 2006). These hedonic hotspots may help to stimulate visceral impulses like cravings, and may amplify the impact of sensory pleasures (Smith et al., 2010). Therefore, in response to an ad for a pleasurable food, emotional memories may help to increase cravings. Hypothesis 1a predicts that high affect intensity individuals, compared to their low affect intensity counterparts, will report stronger emotional memories, which in turn will be associated with stronger cravings and food-related behavioral intentions (see Fig. 1).

\section{Impulse control}

Consumers tend to vary in the extent to which they possess the capacity to deal with the tug-of-war between hedonic impulses versus self-control (Baumeister \& Heatherton, 1996; Hofmann et al., 2009; Tice et al., 2001). People with strong impulse control can inhibit their desires and cravings for short-term rewards in order to pursue more long-term goals (Tice et al., 2001). In the case of eating, impulse control is often about stifling the desire for unhealthy (high sugar and high fat) foods that can lead to weight gain, in the pursuit of long-term goals (e.g. maintaining a healthy weight; Baumeister \& Heatherton, 1996). However, the excitation of emotions often undermines impulse control, thus stimulating the desire for immediate gratification (Tice et al., 2001).

In spite of the plethora of research on personality traits associated with impulse control and impulse buying (Rook \& Gardner, 1993; Verplanken \& Herabadi, 2001), very little is known about whether affect intensity is linked to impulse control. Because high affect intensity individuals tend to respond to the affective component of specific situations (Larsen, Diener, \& Cropanzano, 1987; Larsen et al., 1996), they may be more influenced by the more impulsive emotional system rather than the more reflexive and deliberative self-control system (Hofmann et al., 2009). Thus, hypothesis $1 \mathrm{~b}$ predicts that high affect intensity individuals, compared to their low affect intensity counterparts, will have weaker impulse control, and this lack of impulse control will be associated with stronger cravings and behavioral intentions. These relationships are tested in Study 1 using mediation models (see Fig. 1).

\section{Pleasure anticipation}

The anticipation of pleasure stimulates appetitive desire, encouraging individuals to seek out specific stimuli (Alba \& Williams, 2013; Gard, Gard, Kring, \& John, 2006; Lowe \& Butryn, 2007; Lowe et al., 2009). Food can be a very powerful motivator of sensory pleasure (Elder \& Krishna, 2010; Shiv \& Fedorikhin, 2002), but much is yet to be discovered about how anticipating such pleasure is associated with cravings and behavioral impulses (Moore, 2014). Neuroscientists have shown that the anticipation of pleasant tastes activates significantly more regions of the brain than the actual tasting of the substance itself (O'Doherty, Deichmann, Critchley, \& Dolan, 2002).

One unexplored question is whether high affect intensity individuals experience more pleasure anticipation in the pursuit of sensory experiences (Krishna, 2012). These individuals focus more on emotional details of stimuli, and have a greater capacity for sensory and emotional arousal (Larsen \& Diener, 1987; Larsen et al., 1987; Larsen et al., 1996). Interestingly, among the multiple dimensions of the affect intensity construct (Bagozzi \& Moore, 2011), it is possible that positive affectivity, rather than negative affectivity, may be a better predictor of pleasure anticipation (Gard et al., 2006; Lowe et al., 2009). Positive affectivity measures the tendency to experience intense pleasant feelings (Cropanzano, Weiss, Hale, \& Reb, 2003), and 
should therefore make a unique contribution in understanding the domain of food enjoyment and cravings (Bagozzi \& Moore, 2011). Thus, in Study 2 we take the opportunity to examine the relationship between positive affectivity and sensory stimulation. Hypothesis 2 therefore predicts that when people who are high in positive rather than negative affectivity are exposed to a vivid food advertisement, they experience more pleasure anticipation, which is then associated with stronger food cravings and behavioral intentions. In other words, the impact of positive affectivity on appetitive craving and behavioral intentions will be mediated by pleasure anticipation (Alba \& Williams, 2013; Gard et al., 2006).

\section{Testing potential moderators}

In Studies 3 and 4, we propose two potential moderators of the relationship between affect intensity and consumption-related outcomes. One moderator involves consumption-relevant advertisement features - vivid versus pallid images of food (Studies 3 \& 4) and the other is an individual difference variable - restrained versus unrestrained eating (Study 4).

\section{Can vivid advertising features trigger cravings?}

Dual processing models make distinctions between a more vivid system that is fast, emotionally evocative, and impulsive, versus a more pallid system that is slower, more deliberative, and self-controlled, thereby encouraging more cognitive reflection (Hofmann et al., 2009; Metcalfe \& Mischel, 1999; Xu \& Labroo, 2014). Vivid advertisements stimulate stronger emotional reactions and sensory imaginations than the pallid ones that focus on mere factual information (Anand-Keller \& Block, 1997; Edell \& Burke, 1987; Moore et al., 1995). Presumably, vivid formats are more likely to activate the affective system, thereby evoking emotions and visceral impulses like cravings (Loewenstein \& O'Donoghue, 2007). Related research finds that the brightness of ambient light in the decision environment can increase the perception of heat or warmth, and this experience itself can trigger the hot affective system (Xu \& Labroo, 2014). This reaction in turn magnifies sensation seeking (Zuckerman, 1979), thereby prompting a greater desire for spicy foods (Xu \& Labroo, 2014). Advertising appeals that activate the hot affective system have been shown to be more persuasive than non-emotionally-charged information-laden approaches (Edell \& Burke, 1987; Moore et al., 1995). However, it is still unclear whether emotionally evocative advertisements can indeed stimulate visceral drive states like food cravings. In Study 3, Hypothesis 3 predicts that high affect intensity people will experience more cravings than low affect intensity respondents only in the presence of vivid product descriptions, and not when exposed to more pallid, information-oriented advertising descriptions.

\section{Consumption-relevant individual differences as moderators}

In Study 4, we use the positive affectivity sub-dimension rather than the total affect intensity scale (Larsen \& Diener, 1987), because positive affectivity is likely to be more related to food anticipatory outcomes, and therefore may be more interpretable than the total AIM scale (Bagozzi, 1994). Using the positive affectivity sub-scale also provides an opportunity to compare its predictive ability with that of the negative affectivity sub-scale (Bagozzi \& Moore, 2011). In essence, we examine the extent to which positive affectivity influences appetitive craving, salivation, and behavioral intentions through the moderating role of two consumption-relevant individual difference variables: (a) vivid versus pallid advertising appeals; and (b) dieting status: whether respondents are dieting versus not dieting (see Fig. 1).

\section{Vivid versus pallid advertising appeals}

Vivid advertising formats are likely to stimulate the affective or impulsive system thereby triggering visceral impulses like craving which in turn may lead to salivation and strong desires to eat (Hoch \& Loewenstein, 1991; Hofmann et al., 2009). Researchers have also shown that exposure to the sight and smell of food can stimulate significant increases in cravings and salivation (Gross \& Levenson, 1993; Nederkoorn \& Jansen, 2002; Rogers \& Hill, 1989). If high positive affectivity people experience more cravings in response to vivid food stimuli, they may also show increased salivation compared to negative affectivity respondents. Hypothesis $4 \mathrm{a}$ therefore predicts that high positive affectivity respondents, compared to their negative affectivity counterparts, will generally salivate more after exposure to vivid rather than pallid food images in advertising appeals.

\section{Dieting versus non-dieting eaters}

Despite the plethora of research on the impact of salivary response on food consumption decision making (Krishna et al., 2014; Nederkoorn et al., 2000), there is still a gap in our understanding of the manner in which dieting practices can influence the extent to which positive affectivity can trigger salivation (LeGoff \& Spigelman, 1987; Nederkoorn \& Jansen, 2002). Dieters tend to suppress physiological urges to eat in order to avoid weight gain (Fedoroff et al., 2003). Chronic dieters who suppress their physiological urges tend to have heightened salivation responses to food stimuli (Brunstrom, Yates, \& Witcomb, 2004; LeGoff \& Spigelman, 1987). Furthermore, this salivation response to food is correlated with the extent to which dieters are emotionally connected to food (Canetti, Bachar, \& Berry, 2002; Gardner et al., 2014; Scott, Nowlis, Mandel, \& Morales, 2008). People who are high in positive affectivity will be strongly responsive to emotional arousal and the enjoyment of sensory experiences (Larsen \& Diener, 1987; Larsen et al., 1996; Moore \& Homer, 2000). It is therefore expected that dieters with high positive affectivity will salivate more when exposed to vivid food cues (Canetti et al., 2002; Gardner et al., 2014; Scott et al., 2008). Moreover, to illustrate the interplay of dieting status, positive affectivity, and vividness, Hypothesis $4 \mathrm{~b}$ predicts that for dieters who are exposed to vivid ads, positive affectivity will play a significant role in increasing salivation responses. However, the role of 
positive affectivity will remain non-significant after exposure to pallid food images.

Interestingly, however, research finds that increased salivation does not necessarily lead to increased food consumption (Fedoroff, Polivy, \& Herman, 1997). Exposure to food temptations that exceeds a critical level of intensity can activate defensive strategies that may motivate dieters to inhibit their eating (Fishbach, Friedman, \& Kruglanski, 2003; Geyskens, Dewitte, Pandelaere, \& Warlop, 2008). Dieters tend to use cognitive suppression as a defensive strategy to control food intake (Nederkoorn \& Jansen, 2002). We speculate that although dieters may be more physiologically reactive to food (i.e, high levels of salivation) than non-dieters, they may self-report being unaffected by these cues by reporting lower levels of behavioral intentions. It is therefore possible that these restrained eaters may actually under report the quantity of food they really desire to eat after exposure to vivid ads. This should be especially true for high positive affectivity respondents, compared to high negative affectivity respondents, because of their high reactivity to the vivid food cues. Hypothesis $4 \mathrm{c}$ therefore predicts that when dieters are exposed to vivid (versus pallid) food images, those who are high in positive affectivity will express intentions to eat less food than those who are low in positive affectivity.

\section{The current studies}

In four studies, we examine the relationship between affect intensity and consumption-related responses (Fig. 1). Studies 1 and 2 examine three potential mediators of the relationship between affect intensity and cravings after exposure to vivid food cues. Study 3 examines whether high affect intensity individuals respond with more cravings after exposure to vivid product descriptions rather than pallid ones. In Study 4 we again examine the role of external advertising-related cues that vary in their vividness and pallidness, and also compared behavioral intentions to physiological responses (i.e. salivation). Taken together, these studies point to mediators and moderators that help to explain why and when affect intensity is associated with the desire for unhealthy foods.

\section{Study 1}

Study 1 examines how two psychological processes can help to explain why affect intensity stimulates food cravings and behavioral intentions when exposed to vivid descriptions, namely: emotional memories (Hamann, 2001) and impulse control (Baumeister, 2002; Hofmann et al., 2009; Tice et al., 2001). In Study 1 participants were exposed to a vivid advertisement for a pleasurable food product. We expected that high affect intensity individuals would be more likely to activate emotional memories related to this anticipated consumption experience, which would in turn predict more food cravings. In other words, we expected that emotional memories would mediate the relationship between affect intensity and behavioral intentions (e.g. buying or eating; Fig. 1). In Study 1 lower levels of impulse control are also expected among high affect intensity individuals, and these should be associated with stronger cravings and increased behavioral intentions to eat or buy unhealthy food items (Hofmann et al., 2009). For this reason, impulse control may also play a mediating role in determining the extent to which affect intensity is related to cravings and behavioral intentions.

\section{Method}

Participants, design, and procedure

Using a cross-sectional design, 197 undergraduates (112 females) were exposed to a vivid description of Cinnabon ${ }^{\mathrm{TM}}$ rolls (see Appendix A) with the cover story that the study aimed to investigate the pleasures of eating among college students.

\section{Measures}

Participants first completed the 40-item Affect Intensity Measure (e.g. "My emotions tend to be more intense than those of most people;" 1 = Never, 6 = Always; Larsen \& Diener, 1987). Appetitive craving was measured with three items $(\alpha=.94)$ : (1) "I have a strong desire to eat a Cinnabon ${ }^{\mathrm{TM}}$ roll"; (2) "The description made me have strong cravings for a Cinnabon" ${ }^{\mathrm{TM}}$ roll"; (3) "When I experience a craving desire for a Cinnabon ${ }^{\mathrm{TM}}$ roll it is very intense" ( 1 = Strongly Disagree; 9 = Strongly Agree).

There were two hypothesized mediators of the affect intensity-craving relationship. First, emotional memory $(\alpha=.94)$ was measured with the following items: (1) "Merely reading the description makes me think of the aroma of a Cinnabon ${ }^{\mathrm{TM}}$ roll"; (2) "The memory of the aroma itself stimulates my cravings" ( $1=$ Strongly Disagree; $9=$ Strongly Agree). To measure poor impulse control $(\alpha=.84)$, respondents were given the following instructions: Sometimes descriptions of food may stimulate your thoughts (e.g., is it good or bad for you), or your feelings. Please indicate the extent to which the description of the Cinnabon ${ }^{\mathrm{TM}}$ roll stimulated: (1) your thoughts versus your feelings; (2) your will power versus your desire; (3) your prudent self versus your impulsive self; (4) your rational side versus your emotional side; (5) your head versus your heart (1-9 scales; Shiv \& Fedorikhin, 2002).

To measure behavioral intentions $(\alpha=.92)$, participants indicated the likelihood that they would: (1) take a quick Cinnabon ${ }^{\mathrm{TM}}$ roll snack if you had the chance now, (2) sample a Cinnabon ${ }^{\mathrm{TM}}$ roll if you had the chance right now, (3) stop by a Cinnabon ${ }^{\mathrm{TM}}$ store if you were out shopping now, (4) buy a Cinnabon $^{\mathrm{TM}}$ roll in the near future $(1=$ Very Unlikely; $9=$ Very Likely).

Hunger was assessed at the beginning of the study and again after product exposure $(1=$ Strongly Disagree; $9=$ Strongly Agree), in order to rule out the possibility that hunger could have influenced participants' responses.

\section{Results}

We conducted all mediation analyses using bootstrapped multiple regression analyses with bias-corrected $95 \%$ confidence estimates and 5000 bootstrap resamples (Preacher \& 
Hayes, 2004, 2008). All results report unstandardized regression coefficients.

\section{Hunger}

There was no relationship between affect intensity and hunger when the study began, making it unlikely that baseline hunger level was a confound, $r(197)=.08, p=.27$. However, high affect intensity respondents are expected to be more susceptible to vivid food descriptions, and indeed, we found a correlation between affect intensity and hunger after food exposure, $r(197)=.26, p<.001$. A mixed-model repeated measures ANOVA found that high affect intensity scorers increased in hunger from the beginning $(M=5.37, S D=.50)$ to the end $(M=5.90, S D=.43)$ of the study, while low affect intensity scorers actually decreased in hunger from the beginning ( $M=$ $4.76, S D=.49)$ to the end $(M=3.88, S D=.42)$ of the study, $F_{(1,81)}=3.92, p=.05$

\section{Emotional memory as mediator}

We first tested emotional memory as a mediator of the affect intensity-craving relationship. Affect intensity was associated with more emotional memories, $a$ path: $B=.04, t(195)=3.92$, $p<.001$, and in turn, emotional memory was associated with more cravings, $b$ path: $B=.78, t(195)=15.20, p<.001$. Affect intensity was also directly associated with more cravings, $c$ path: $B=.03, t(195)=2.80, p=.006$. The direct effect of affect intensity on craving was no longer significant when controlling for emotional memory, which suggests full mediation, $c^{\prime}$ path: $B=-.001, t(195)=-.12, p=.90$. The mediating role of emotional memories in the relationship between affect intensity and craving is further confirmed by the indirect effects test, $B=.03 ; \mathrm{CI}=.02$ to .05 ; see Fig. 2a).

We next tested emotional memory as a mediator of the affect intensity-behavioral intention relationship. Affect intensity was associated with more emotional memories, $a$ path: $B=.04$, $t(195)=3.92, p<.001$, and in turn, emotional memory was associated with more behavioral intentions, $b$ path: $B=.67$, $t(195)=9.78, p<.001$. Affect intensity was also directly associated with more behavioral intentions, $c$ path: $B=.03$, $t(195)=1.94, p=.05$. The direct effect of affect intensity on behavioral intentions was no longer significant when controlling for emotional memory, suggesting full mediation, $c^{\prime}$ path: $B=-.004, t(195)=-.36, p=.72$. The mediating role of emotional memories in the relationship between affect intensity and behavioral intentions is further confirmed by the indirect effects test, $B=.03$; CI $=.02$ to .05 ; see Fig. $2 \mathrm{~b}$ ).

\section{Poor impulse control as a mediator}

We next examined whether poor impulse control mediated the relationship between affect intensity and craving. Affect intensity was associated with poorer impulse control (higher numbers $=$ worse),$a$ path: $B=.03, t(195)=3.56, p<.001$, and in turn, poor impulse control was associated with more cravings, $b$ path: $B=.82, t(195)=10.43, p<.001$. Affect intensity was also directly associated with more cravings, $c$ path: $B=.03, t(195)=2.80, p=.006$. The direct effect of affect intensity on craving was no longer significant when controlling for emotional memory, $c^{\prime}$ path: $B=.01, t(195)=$ $.81, p=.42$. The mediating role of poor impulse control in the relationship between affect intensity and craving is further confirmed by the indirect effects test, $B=.03$; $\mathrm{CI}=.01$ to .04 ; see Fig. 2c).

We next tested whether poor impulse control would mediate the affect intensity-behavioral intention relationship. Affect intensity was associated with poorer impulse control (higher numbers $=$ worse), $a$ path: $B=.03, t(195)=3.56, p<.001$, and in turn, poor impulse control was associated with more behavioral intentions, $b$ path: $B=.94, t(195)=11.22, p<.001$. Affect intensity was also directly associated with more behavioral intentions, $c$ path: $B=.03, t(195)=1.95, p=.05$. The direct effect of affect intensity on behavioral intentions was no longer significant when controlling for emotional memory, $c^{\prime}$ path: $B=-.003, t(195)=-.36, p=.72$. The mediating role of poor impulse control in the relationship between affect intensity and craving is further confirmed by the indirect effects test, $B=.03$; $\mathrm{CI}=.01$ to .05 ; see Fig. $2 \mathrm{~d}$ ).

\section{Discussion}

Study 1 demonstrated that affect intensity is correlated with more food cravings and behavioral intentions to eat or buy food. We also identified two mediators of the relationship between affect intensity and these consumption-related outcomes. High affect intensity scorers experience more cravings and behavioral intentions because they have more emotional memories and poorer impulse control. Study 2 will examine how affect intensity is linked to a third potential mediator, pleasure anticipation, which can stimulate food cravings and influence behavioral intentions (Gard et al., 2006; Lowe \& Butryn, 2007; Lowe et al., 2009).

\section{Study 2}

Study 2 aimed to demonstrate that when high affect intensity individuals are exposed to a vivid food advertisement, they experience more pleasure, which is then associated with stronger food cravings and increased behavioral intentions. Hence, pleasure anticipation may also be a mediator of the relationship between affect intensity and consumption-related outcomes (Fig. 1). Study 2 also examined which of the six affect intensity subscales would best predict cravings and behavioral intentions via pleasure anticipation. These subscales were not available in Study 1. The positive affectivity subscale assesses the degree to which individuals experience intense positive feelings. As such, it is quite relevant to anticipating or seeking pleasurable experiences, including food. Thus, in Study 2 , we examined whether positive affectivity (versus negative affectivity) is implicated in the link between affect intensity and consumption-related outcomes. We did so by examining relationships between these affect intensity subscales and each consumption-related outcome (i.e. craving, behavioral intentions), and then testing whether pleasure anticipation was a plausible mediator in the presence of a significant relationship. 
a)

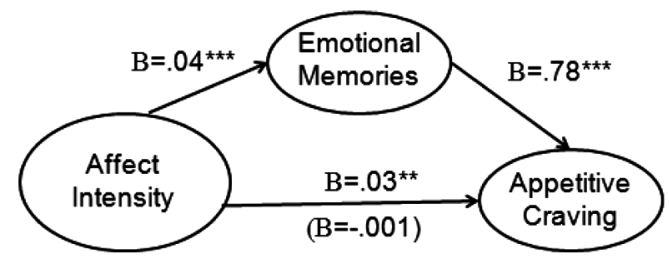

b)

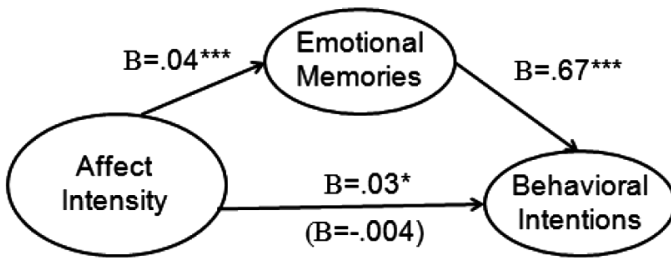

c)

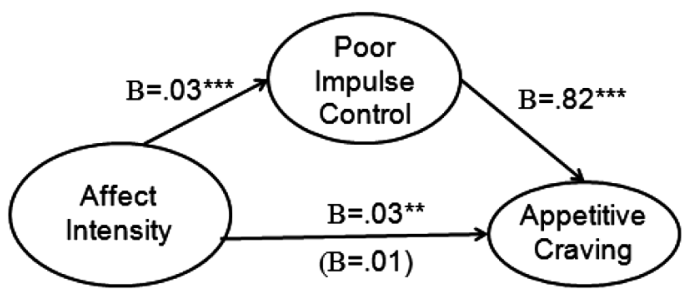

d)

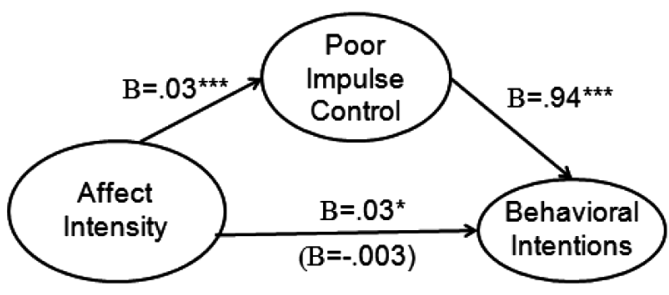

Note. Mediation analyses were conducted using bootstrapped multiple regression analyses with bias-corrected $95 \%$ confidence estimates and 5000 bootstrap resamples (Preacher \& Hayes, 2004; 2008). All results report unstandardized regression coefficients. ${ }^{*} \mathrm{p}<.05,{ }^{*} \mathrm{*}<<.01$,

$* * * \mathrm{p}<.001$

Fig. 2. The mediating role of emotional memories (Figs. 2a and b) and poor impulse control (Figs. 2c and d) on appetitive craving and behavioral intentions in Study 1 .

\section{Method}

Participants, design, and procedure

In a cross-sectional design, 130 undergraduate volunteers (42 females) were told that the goal of the study was to gain a deeper understanding of the eating habits of college students. They first read a vivid description of a pizza (see Appendix A), and then responded to a series of dependent measures.

\section{Measures}

The measures used for affect intensity $(\alpha=.86)$, craving intensity $(\alpha=.84)$, and behavioral intentions $(\alpha=.92)$ were identical as in Study 1. The positive affectivity subscale has 17 items (e.g. "When something good happens, I am usually more jubilant than others;" $\alpha=.85$ ) and the negative affectivity subscale has 6 items (e.g. "Sad movies deeply touch me;" $\alpha=$ .56). Pleasure anticipation was assessed with two statements
( $\alpha=.76$ ): (a) "Just before I taste a favorite food, I feel intense anticipation"; and (b) "When I taste a favorite food, I feel intense pleasure" ( 1 = Strongly Disagree; 5 = Strongly Agree: Lowe et al., 2009). Hunger was assessed at the beginning of the study ( 1 = Strongly Disagree; 9 = Strongly Agree).

\section{Results}

There was no relationship between affect intensity and hunger before the start of the experiment, $r(130)=-.09, p=.33$, minimizing its likelihood as a confound.

\section{Mediation model with positive affectivity subscale}

We first tested pleasure anticipation as a mediator of the positive affectivity-craving relationship. Positive affectivity was associated with more pleasure anticipation, $a$ path: $B=.65$, $t(128)=5.73, p<.001$, and in turn, pleasure anticipation was associated with more cravings, $b$ path: $B=1.03, t(195)=5.06$, 
$p<.001$. Positive affectivity was also marginally associated with more cravings, $c$ path: $B=.52, t(195)=1.83, p=.069$. The direct effect of positive affectivity on craving no longer approached significance when controlling for pleasure anticipation, which suggests full mediation, $c^{\prime}$ path: $B=-.15, t(195)=-.50, p=.62$. The mediating role of pleasure anticipation in the relationship between positive affectivity and craving is further confirmed by the indirect effects test, $B=.67$; $\mathrm{CI}=.40$ to 1.03 ; see Fig. 3a).

We next tested pleasure anticipation as a mediator of the relationship between positive affectivity and behavioral intentions. Positive affectivity was associated with more pleasure anticipation, $a$ path: $B=.65, t(128)=5.73, p<.001$, and in turn, pleasure anticipation was associated with more behavioral intentions, $b$ path: $B=.95, t(195)=4.24, p<.001$. Positive affectivity was also directly associated with more behavioral intentions, $c$ path: $B=.87, t(195)=2.84, p=.005$. The direct effect of positive affectivity on behavioral intentions was no longer significant when controlling for pleasure anticipation, which suggests full mediation, $c^{\prime}$ path: $B=.25, t(195)=.78$, $p=.44$. The mediating role of pleasure anticipation is further confirmed by the indirect effects test, $B=.62 ; \mathrm{CI}=.32$ to .99 ; see Fig. 3b).

\section{Mediation model with negative affectivity subscale}

Negative affectivity was unrelated to cravings, $\beta=-.02$, $p=.81$, and behavioral intentions, $\beta=-.03, p=.73$, and only marginally related to pleasure anticipation, $\beta=.15, p=.09$. Therefore, no mediation analyses were conducted with the negative affectivity subscale.

\section{Mediation model with other subscales}

Although the guilt subscale ( $\alpha=.87$ ) was positively related to pleasure anticipation, $\beta=.30, p=.001$, it was unrelated to craving, $\beta=.05, p=.58$, and behavioral intentions, $\beta=.07$, $p=.41$. Therefore, no mediation analyses were conducted. Although the identity threat subscale $(\alpha=.66)$ was positively related to pleasure anticipation, $\beta=.37, p<.001$, it was unrelated

a)

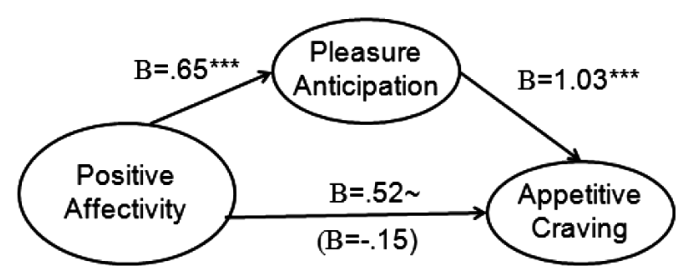

b)

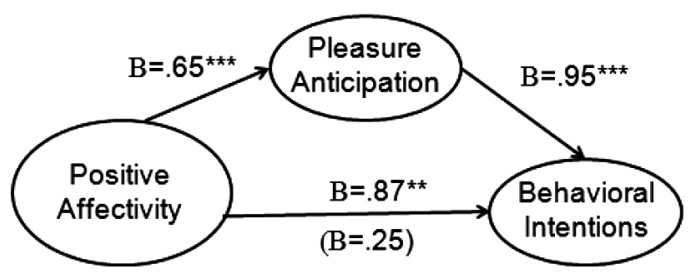

Fig. 3. The mediating role of pleasure anticipation on appetitive craving (Fig. 3a) and behavioral intentions (Fig. 3b) in Study 2. to craving, $\beta=.02, p=.84$, and behavioral intentions, $\beta=.04$, $p=.64$. Therefore, mediation analyses were not possible. The serenity subscale $(\alpha=.81)$ was unrelated to craving, $\beta=.05, p=$ .58 , behavioral intentions, $\beta=.03, p=.72$, and pleasure anticipation, $\beta=-.01, p=.93$. Therefore, no mediation analyses were conducted. Finally, the general (i.e. non-valenced) affect intensity subscale $(\alpha=.51)$ was unrelated to craving, $\beta=-.04$, $p=.63$, behavioral intentions, $\beta=-.01, p=.90$, or pleasure anticipation, $\beta=.11, p=.21$. Therefore, no mediation analyses were conducted.

\section{Discussion}

In Study 2 we confirmed that people who experience intense emotions, especially positive ones, also experience more intense levels of pleasure anticipation, which is subsequently associated with cravings and behavioral intentions. This has interesting implications for marketing strategists. It is a reminder of the limitations in the assumption that consumers are homogeneous in their reactions to marketing stimuli designed to stimulate purchase impulses. It also suggests that ads that feature the anticipation of the pleasure of consumption experiences will have a stronger hedonic impact on high affect intensity consumers, and especially those high on positive affectivity - a shorter and more efficient measurement of affect intensity.

One limitation of Studies 1 and 2 is that there are conceptually overlapping items in the mediating variables (i.e. emotional memory, impulse control, pleasure anticipation), making it possible that some of our results are explained by common method bias. Thus, the challenge for future studies examining potential mediators of the relationship between affect intensity and consumption-related responses is to try to find mediators that rely on other assessments. Future researchers might attempt to operationalize mediators such as pleasure anticipation in more behavioral terms. For example, researchers could use eye tracking software to examine which features of relevant images (e.g. advertisements) high affect intensity people focus on, to see if a focus on more hedonic parts of the image mediates the affect intensity-consumption relationship. Implicit association tests could also be used to examine whether high affect intensity people have stronger cognitive associations (i.e. faster response times) between desired consumption products (e.g. Cinnabon ${ }^{\mathrm{TM}}$ rolls) and positive words (e.g. happy, pleasure). Despite this limitation, across two studies we demonstrated three important psychological mediators of the relationship between affect intensity and consumption-related outcomes, demonstrating the importance of the positive affectivity subscale in particular.

\section{Study 3}

We now turn to potential moderators of the relationship between affect intensity and consumption-related responses (Fig. 1). Toward this goal, Study 3 examines whether higher affect intensity is associated with more appetitive cravings in the presence of vivid, but not pallid, product descriptions. Vivid advertising formats are more likely to activate the affective 
system, thereby evoking emotions and visceral impulses like cravings (Hoch \& Loewenstein, 1991; Loewenstein \& O'Donoghue, 2007). Therefore, we predict that high affect intensity people will experience more cravings than low affect intensity respondents only in the presence of vivid product descriptions, and not when exposed to more pallid advertising descriptions.

\section{Method}

Participants, design, and procedure

Participants were 226 undergraduates (90 females). Affect Intensity (high versus low) was a grouping factor and Product Description (Vivid versus Pallid) was manipulated as a betweensubjects factor. Two different ads (one for cookies, and the other for pizza) were nested in each of the two product description conditions (within-subjects). During prescreening, 457 undergraduates were administered the Affect Intensity Measure (Larsen \& Diener, 1987).We pre-selected respondents from the upper and lower quartiles, who participated in a supposedly unrelated study two weeks later. Participants were exposed to two product types (i.e., cookies and pizza, counterbalanced order), seeing either: (a) a vivid, pleasure-focused version featuring emotionally evocative product descriptions, or (b) a pallid, information-focused, version that presented the nutritional value of the products (see Appendix A). Both versions were cast in the same scenario: 'You and a friend are shopping at the mall.' Research suggests that narrative or story-based processing can increase self-identification with products and affect later product-related responses (Escalas, 2004). Participants in the vivid condition saw vivid versions of cookies and pizza, and similarly for the pallid condition. Participants next answered dependent measures, in counterbalanced order.

\section{Measures}

\section{Affect intensity}

Upper and lower quartile splits were derived from the Affect Intensity Measure (Larsen \& Diener, 1987), to prescreen for high versus low affect intensity participants (Moore et al., 1995). ${ }^{1}$ Appetitive craving was measured with three items per product (cookies: $\alpha=.94$; and for pizza: $\alpha=.91$ ): "I have a strong desire to eat cookies (pizza)"; "The craving I have right now for cookies (pizza) can be described as very strong"; "My desire for cookies (pizza) is so strong I can feel my mouth watering" ( 1 = Strongly Disagree; 5 = Strongly Agree: Cepeda-Benito et al., 2000). The time of day was recorded as a proxy for hunger, which could have influenced craving intensity ( $1 \mathrm{pm}, 2 \mathrm{pm}$, or $3 \mathrm{pm})$. Order of exposure to food item (cookie versus pizza) was recorded to rule out order effects. One key characteristic of food craving is that individuals are tempted to yield to their impulses, with vivid descriptions more tempting than pallid ones (Geyskens et al., 2008). For the manipulation check, participants were thus asked to respond to the following statement: "The description of the cookies (pizza) was very tempting" $(1=$ Strongly Disagree; $5=$ Strongly Agree).

\section{Results}

\section{Controls and manipulation check}

Time of day was unrelated to craving intensity (cookies: $F_{(1,223)}=1.89, p=.17$; pizza: $\left.F_{(1,223)}=.33, p=.56\right)$. The order of ad exposure also had no significant influence on cravings (cookies: $F_{(1,223)}=2.26, p=.10$; pizza: $F_{(1,223)}=1.34, p=.26$ ). Thus, these variables were not covariates in the analyses. The vivid condition for both cookies $(M=2.39)$ and pizza $(M=2.42)$ was more tempting than the pallid condition (cookies: $M=1.97$, $F_{(1,226)}=7.94, p<.005$; pizza: $M=2.09, F_{(1,226)}=5.26$, $p<.02)$.

\section{The effects of affect intensity and product description on cravings}

Affect intensity was related to cravings for cookies $\left(M_{H i}{ }_{A I}=2.82\right.$ versus $\left.M_{\text {Low } A I}=2.54\right), F_{(1,223)}=3.82, p=$ .052 ; but not pizza $\left(M_{H i} A I=2.84\right.$ versus $\left.M_{\text {Low } A I}=2.68\right)$, $F_{(1,223)}=1.38, p=.24$. Product description significantly affected cravings for cookies $\left(M_{\text {vivid }}=3.15\right.$ versus $\left.M_{\text {pallid }}=2.21\right)$; $F_{(1,223)}=43.63, p<.001$, and pizza $\left(\mathrm{M}_{\text {vivid }}=3.31\right.$ versus $\left.M_{\text {pallid }}=2.21\right) ; F_{(1,223)}=65.96, p<.001$.

However, these main effects were qualified by significant Affect Intensity x Product Description interactions on cravings for cookies, $F_{(1,223)}=6.25, p=.01$, and pizza, $F_{(1,223)}=4.25$, $p=.04$ (Fig. 4). In the vivid cookie condition, high affect intensity individuals reported stronger cravings $\left(M_{H i} A I=3.47\right)$ than low affect intensity individuals $\left(M_{\text {Low } A I}=2.83\right), F_{(1,111)}=$ $9.57, p=.003$. In contrast, in the pallid condition, high and low affect intensity participants reported similar levels of cravings $\left(M_{H i A I}=2.17\right.$ versus $\left.M_{\text {Low } A I}=2.25\right), F_{(1,112)}=.16, p=.70$. In the vivid pizza condition, high affect intensity respondents reported stronger cravings $\left(M_{H i} A I=3.53\right)$ than low affect intensity respondents $\left(M_{\text {Low } A I}=3.09\right), F_{(1,111)}=4.94, p=.03$. However, in the pallid condition, there were similar levels of cravings between high affect intensity $\left(M_{H i} A I=2.15\right)$ and low affect intensity respondents $\left(M_{\text {Low } A I}=2.27\right), F_{(1,112)}=.42$, $p=.52$.

\section{Discussion}

Study 3 demonstrates that consumption-related advertisement features moderate the relationship between affect intensity and consumption-related outcomes (Fig. 1). In other words, vivid advertisements have different effects on people depending on their levels of affect intensity: high affect intensity people are especially susceptible to such ads. One limitation of Study 3 is that the control condition representing the pallid version of the advertising appeal focused on nutritional information which could have primed a wider range of irrelevant issues, thus possibly undermining the integrity of the ad type manipulation. In Study 4 we address this concern by only varying one specific feature of the advertisement- the 


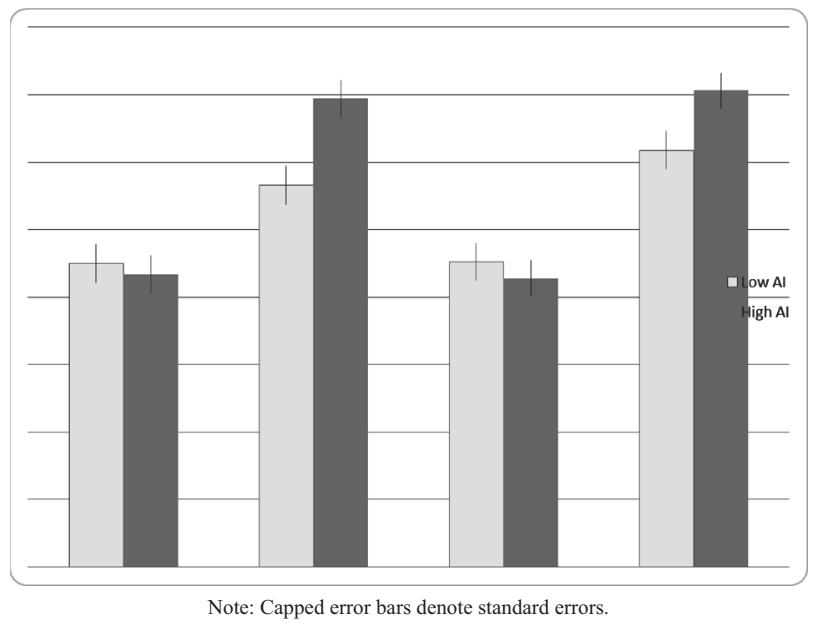

Fig. 4. The moderating effect of product description on the cravings of high and low affect intensity participants (Study 3 ).

picture of the stimulus (pizza) was presented in color (vivid) versus in black and white (pallid).

\section{Study 4}

In Study 4, we explore the novel possibility that high positive affectivity people salivate more in response to vivid food cues. In this context, we also aim to determine whether dieting status (restrained versus unrestrained eating) moderates the relationship between positive affectivity and responses to vivid food cues. Dependent measures are: cravings, physiological responses (i.e. salivation responses to pizza image), and behavioral intentions (i.e. number of desired slices to eat). In preparation for Study 4, a pilot study was conducted to justify the distinction between the updated vivid versus pallid manipulation.

\section{Pilot study}

Participants were 127 undergraduates (44 females), with the following cover story: "Sorzano ${ }^{\circledR}$, an Italian pizza restaurant is scheduled to open a new store in our downtown district and is currently conducting a series of studies to test consumers' reactions to their new line of pizzas." The vivid version featured a full color image of a pizza slice, with delicious red and green pepper toppings, and a generous coating of golden mozzarella cheese oozing off the slice. This picture was designed to stimulate cravings. The pallid version featured a black and white picture of the same pizza slice (see Pictures $1 \mathrm{a}$ and $1 \mathrm{~b}$ in Appendix A).

Cravings were assessed via five items $(\alpha=.91)$ : "I have a strong desire to eat Sorzano pizza"; "This ad makes my mouth water for Sorzano pizza"; "I have strong cravings for a Sorzano pizza"; "I can imagine the taste of the pizza shown in the ad"; and "I can imagine holding a warm slice of the pizza in my hands" ( 1 = Strongly Disagree; $9=$ Strongly Agree). Vividness was measured with the same endpoints $(\alpha=.84)$ : "The picture of the pizza is visually appealing"; and "The picture of the pizza is vivid." Indeed, the vivid picture stimulated more intense cravings $(M=5.28)$ than the pallid one $(M=4.55), F_{(1,24)}=5.09, p=.03$, and higher ratings of vividness $(M=6.39)$ compared to the pallid one $(M=4.85), F_{(1,124)}=16.83, p<.001$. Having verified the effectiveness of this subtle manipulation, we proceeded to use it in Study 4.

\section{Study 4}

\section{Method}

\section{Participants and design}

Participants were 99 undergraduates (67 females) who were given the same cover story as in the pilot study. We examined the joint effects of positive affectivity, dieting status (dieting or not), and type of advertisement (vivid versus pallid) in predicting appetitive cravings, physiological responses, and behavioral intentions (Fig. 1). Forty percent of the sample reported that they were currently dieting. Dieting status did not differ by gender, $\chi(1)=.36, p=.56 \quad$ (males $=44 \%$, females $=38 \%$ ), nor were there gender differences in positive affectivity, $F_{(1,96)}=2.59, p=.11$.

\section{Procedure}

Participants were asked to refrain from eating or drinking at least two hours before coming to the lab $(M=4.89 \mathrm{~h}$ since eating). All participants were first shown a control image (a local paper store) on a survey website. This was to assess individual differences in salivation without a food stimulus. Dental rolls were first weighed dry with a high-precision food scale $(0.01 \mathrm{~g}$ gradations). They were then placed in participants' mouths for $2 \mathrm{~min}$ while viewing the image to assess salivation responses. Dental rolls were then weighed a second time. The salivation response was calculated as the post-image minus the pre-image dental roll weight.

Participants next completed a questionnaire on the survey website. Baseline hunger levels and affect intensity were assessed using the same procedures as in the previous studies. Participants also reported their typical number of pizza slices eaten. Participants were next randomly assigned to see vivid (color) or pallid (black and white) images of pizza (Appendix A). Dental rolls were placed for a 2 minute period to assess their salivation responses to the pizza.

Participants were asked a number of questions about their responses to the images. Of most interest to the current study were their appetitive cravings and behavioral intentions. Appetitive craving was measured with three items $(\alpha=.86)$ : "I have a strong desire to eat a Sorzano pizza"; "The advertisements made my mouth water for Sorzano pizza"; and "The advertisements made me have strong cravings for a Sorzano pizza" ( 1 = Strongly Disagree; 7 = Strongly Agree). Eating-related behavioral intentions were assessed by asking: "How many slices do you intend to eat if you could have a large Sorzano pizza right now?"2 


\section{Results}

\section{Correlational analyses}

There was no relationship between positive affectivity and baseline hunger, $r(98)=.08, p=.43$, or the number of hours since participants last ate, $r(96)=-.07, p=.52$. We also examined the relationship between the six affect intensity factors and each potential dependent measure (cravings, salivation, and behavioral intentions). To do so, the six affect intensity factors were simultaneously regressed onto each measure. Positive affectivity was the only significant predictor of cravings, $\beta=.35, p=.008$ (all other $p s>.17$ ). Therefore, analyses were not conducted with the negative affectivity subscale. Separate correlations revealed that craving was significantly correlated with the other two outcome variables: salivation $(r=.27, p=.008)$, and behavioral intentions number of slices desired $(r=.31, p=.002)$. The rest of the analyses focused on salivation and behavioral intentions.

\section{Testing hypotheses with regressions}

We next examined whether dieting status and positive affectivity moderated responses to vivid food cues (Fig. 1). Stepwise linear regression analyses examined the effects of dieting status, positive affectivity, and ad type on: a) physiological responses (i.e. salivation in response to seeing pizza image), and b) behavioral intentions (i.e. number of slices that participant wanted to eat). In Step 1, we examined the main effects of dieting status ( $1=$ dieting, $0=$ not dieting), positive affectivity (mean-centered, continuous), and ad type condition ( $1=$ vivid, $0=$ pallid). In Step 2 we examined all 2 -way interactions, and in Step 3 we examined the 3-way interaction (see Table 1).

\section{Physiological responses-salivation}

Salivation response to the pizza was calculated as follows: salivation response after pizza minus salivation response after control image. In Step 1, the only significant main effect was that high positive affectivity scorers salivated more after seeing the pizza $(\beta=.25, p=.02)$. This finding is consistent with Hypothesis $4 \mathrm{a}$, thus confirming the prediction that people with strong positive affectivity will respond to food stimuli with higher levels of salivation than their negative affectivity counterparts.

Ad type condition $(\beta=.08, p=.45)$ and dieting status $(\beta=-.02, p=.87)$ were unrelated to salivation (Table 1$)$. In Step 2, the only significant effect was a Dieting Status $\times$ Ad type interaction $(\beta=-.32, p=.04)$, indicating that non-dieters salivated more when exposed to the vivid advertisement. The other two-way interactions were non-significant (Ad type $\times$ PA: $\beta=.07, p=.61$; Dieting Status $\times \mathrm{PA}: \beta=.18, p=.23)$. However, the Dieting Status $\times$ Ad type condition interaction was qualified by a 3 -way interaction with positive affectivity $(\beta=.40$, $p=.03)$.
Table 1

Effects of positive affectivity, ad vividness, and dieting status on salivation responses and behavioral intentions in Study 4.

\begin{tabular}{|c|c|c|}
\hline & $\begin{array}{l}\text { Salivation } \\
\text { response }(\beta)\end{array}$ & $\begin{array}{l}\text { Behavioral } \\
\text { intention }(\beta)\end{array}$ \\
\hline \multicolumn{3}{|l|}{ Step 1: main effects } \\
\hline Positive affectivity & $.25^{*}$ & .07 \\
\hline Ad type $(1=$ vivid, $0=$ pallid $)$ & .08 & .06 \\
\hline Dieting status $(1=$ dieting, $0=$ not $)$ & -.02 & $-.16 \sim$ \\
\hline \multicolumn{3}{|l|}{ Step 2: two-way interactions } \\
\hline Dieting $\times$ ad type & $-.32 *$ & -.05 \\
\hline Positive affectivity $\times$ ad type & .07 & .19 \\
\hline Dieting $\times$ positive affectivity & .18 & -.14 \\
\hline \multicolumn{3}{|l|}{ Step 3: three-way interaction } \\
\hline Dieting $\times$ positive affectivity $\times$ ad type & $.40^{*}$ & $-.33 *$ \\
\hline \multicolumn{3}{|l|}{ Split by dieting status } \\
\hline \multicolumn{3}{|l|}{ Dieters } \\
\hline Positive affectivity & $.41^{*}$ & -.08 \\
\hline Ad type & -.17 & .05 \\
\hline Positive affectivity $\times$ ad type & $.40^{*}$ & -.10 \\
\hline \multicolumn{3}{|l|}{ Non-dieters } \\
\hline Positive affectivity & .11 & .14 \\
\hline Ad type & $.25 \sim$ & .05 \\
\hline Positive affectivity $\times$ ad type & -.22 & $.36^{*}$ \\
\hline \multicolumn{3}{|c|}{ Split by dieting status and vividness: correlation with positive affectivity } \\
\hline Non-dieters/pallid & .30 & -.18 \\
\hline Non-dieters/vivid & -.04 & $.29 *$ \\
\hline Dieters/pallid & .32 & -.05 \\
\hline Dieters/vivid & $.55^{*}$ & -.17 \\
\hline
\end{tabular}

$\sim p<.11,{ }^{*} p<.05,{ }^{* *} p<.01$.

In order to interpret this interaction, we split the file into Dieters (40\% of sample) and Non-Dieters $(60 \%)$, and ran regressions predicting salivation responses from Positive Affectivity, Ad type condition, and their interaction. For Dieters, there was a main effect of Positive Affectivity $(\beta=.41, p=.01)$, indicating a significant salivation increase for those with high positive affectivity. However, there was no main effect of Ad type condition $(\beta=-.17, p=.29)$. Importantly, the interaction between Ad type condition and positive affectivity was also significant $(\beta=.40, p=.04)$. This means that for Dieters who were exposed to vivid food cues, positive affectivity played a significant role in increasing salivation responses $(\beta=.55, p=$ $.03)$. This relationship was not significant after exposure to pallid food cues $(\beta=.32, p=.15)$. In other words, for Dieters, this salivation response to vivid cues is strongest for those scoring high in Positive Affectivity. Hypothesis $4 \mathrm{~b}$ was therefore confirmed. In contrast, Non-Dieters show a simple salivation response after seeing vivid food cues $(\beta=.25, p=.07$; Table 1$)$. This indicates that Non-Dieters in the vivid condition salivated marginally more overall, regardless of their Positive Affectivity levels.

\section{Behavioral intentions}

There was a correlation between the number of slices that participants typically eat (reported at baseline), and the number that they intended to eat after seeing the pizza image, $r(96)=.45$, $p<.001$. In addition, a paired-samples $t$-test revealed that 
participants wanted to eat about 1 more pizza slice $(M=3.22$ slices) than they typically would $(M=2.41)$ after seeing any food image, $t(96)=-5.27, p<.001$.

We thus controlled for participants' typical number of slices eaten when examining the effect of each of the predictor variables on the number of pizza slices that participants desired to eat after seeing the food image. Thus, results indicate the number of slices participants want to eat over and above their own typical eating behavior. (Results remain consistent when not adding this covariate.) In Step 1, Ad type condition $(\beta=.06, p=.54)$ and Positive Affectivity $(\beta=.07, p=.48)$ were not related to the number of slices desired (Table 1). The only marginal effect was that Dieters reported wanting to eat fewer slices overall than Non-Dieters $(\beta=-.16, p=.11)$. In Step 2, no significant 2-way effects emerged (all $p \mathrm{~s}>$.14). However, the 3-way interaction between Dieting Status, Positive Affectivity, and Ad type was significant $(\beta=-.33, p=.05)$.

We split the file into Dieters and Non-Dieters, and examined the relationship between Positive Affectivity, Ad Type, and their interaction in predicting behavioral intentions - the number of pizza slices desired. In this case, the Non-Dieters showed the strongest effects. For them, although there was no main effect of Positive Affectivity $(\beta=.14, p=.26)$ or Ad type $(\beta=.05, p=.68)$, there was a significant interaction between them $(\beta=.36, p=.04)$. This means that when Non-Dieters were exposed to vivid food images, those high in positive affectivity wanted to eat more pizza $(\beta=.29, p=.03)$. Yet, for Non-Dieters who were exposed to pallid food images, positive affectivity was unrelated to behavioral intentions to eat pizza $(\beta=-.18, p=.40)$. These results are therefore consistent with Hypothesis $4 \mathrm{c}$ which predicted that when non-dieters are exposed to vivid food images, those who are high in positive affectivity will express intentions to eat more food than those who are restrained dieters.

For Dieters, there was no main effect of Ad Type ( $\beta=.05$, $p=.72)$ or Positive Affectivity $(\beta=-.08, p=.58)$, and there was no interaction $(\beta=-.10, p=.55)$. This finding does lend some degree of support for the expectation that dieters are the ones who would be more reluctant than non-dieters to admit any desire to eat increased quantities of food after exposure to vivid food images. The implication is that although dieters are more physiologically reactive to vivid food cues, especially if they are high in Positive Affectivity, they self-report being unaffected by these cues by reporting lower levels of behavioral intentions. This points to the value of using physiological assessments like salivation that are non-conscious and more difficult to misrepresent.

\section{Discussion}

Study 4 examined the impact of positive affectivity when restrained versus unrestrained eaters were exposed to vivid versus pallid pictures of pizza. First, positive affectivity was the only significant predictor of craving, and craving was significantly correlated with the other two outcome variables: salivation and behavioral intentions to eat a desired number of slices. Next, there was a significant tendency for high positive affectivity participants to respond to vivid food cues with increased salivation, thus confirming a crucial hypothesis that this affect intensity sub-factor uniquely predicts salivation.

Third, we found that non-dieters generally salivated more when exposed to the vivid version of the ad. In contrast, dieters who were exposed to the vivid ad salivated more only when they were high in positive affectivity. This suggests that because dieters are presumed to be more emotionally attached to food (Canetti et al., 2002), they relied more on the emotional boost they received through the positive affectivity dimension of affect intensity (Bagozzi \& Moore, 2011; Larsen et al., 1996). This finding provides support for our general model (Fig. 1) which predicts that ad vividness and dieting status both moderate the effect of positive affectivity on salivation. Fourth, with respect to behavioral intentions, for non-dieters, high positive affectivity individuals admit wanting to eat more after exposure to vivid images; whereas the type of food image makes no difference for dieters, who may be motivated to inhibit their food impulses (Fedoroff et al., 1997). It is interesting to note that dieters with high positive affectivity showed a significant increase in salivation - a non-conscious physiological response. Yet, these dieters seem reluctant to report their actual intentions to eat, resulting in non-significant main and interaction effects for behavioral intentions. Further replications are needed to confirm whether dieters are truly motivated to suppress their true desires to eat in order to maintain a favorable public image.

\section{General discussion}

In modern industrial societies palatable foods and their cues can carry strong motivational power to undermine self-control and trigger impulsive consumption-related outcomes such as cravings, salivation, and behavioral intentions. Consistent with our theoretical model (Fig. 1), Studies 1 and 2 identified three psychological processes that served as mediators of the influence of affect intensity on food cravings, and behavioral intentions to buy and consume the food: (a) the role of emotional memories, (b) the weakening of impulse control, and (c) the higher anticipation of pleasure. Using a person-by-situation interactionist model (Anderson \& Bushman, 2002; Cooper, 2010), Studies 3 and 4 found that these consumption-related outcomes were influenced by individual difference traits associated with affect intensity (Larsen \& Diener, 1987), background characteristics such as dieting status (Fedoroff et al., 2003), and contextual features such as the vividness of the of advertising appeal (Loewenstein \& O'Donoghue, 2007). Studies 2 and 4 further reveal that the positive affectivity factor seems to be most pertinent to these processes. Most remarkably, we were able to demonstrate for the first time that people with high positive affectivity had increased salivation responses, especially when they are dieters who are exposed to vivid food ads (Study 4).

This research makes insightful contributions to theory development in the fields of advertising and consumer behavior. For example, this is one of the first studies to demonstrate that print advertising appeals can directly impact food cravings (Cepeda-Benito et al., 2000; Fedoroff et al., 2003). Moreover, we also find that affect intensity is associated with food cravings, 
especially when moderating conditions such as the vividness of the message are taken into consideration (Loewenstein \& O’Donoghue, 2007). Hitherto, research on affect intensity was limited to individual differences in social affective responses like positive and negative emotions (Larsen \& Diener, 1987; Moore et al., 1995), or differences in sensory arousability and cognitive operations (Larsen et al., 1987). We demonstrate that the differences in visceral motivational drive states like food cravings have implications for behavioral intentions and salivation responses. Affect intensity would also likely be associated with responses to other products to the extent that ads focus on sensory-based product features such as smell, feelings, or tactile features (Kergoat et al., 2012; Krishna, 2012; Krishna \& Schwarz, 2014). These results also confirm a direct link between affect intensity and three psychological processes, thereby opening an interesting discussion about the underlying reasons why affect intensity influences food cravings, and correspondingly, behavioral intentions to consume food.

\section{Mediators of the relationship between affect intensity and consumption-related responses}

The revelation that high affect intensity individuals may be equipped with more sensitive and accessible emotional memories that can be activated by sensory details embedded in an external stimulus (Study 1) represents a significant contribution to the extant literature. This paper provides a contextual application of the notion that emotional memories of palatable food cues may play a key role in activating hedonic hotspots in the brain, which in turn may accelerate cravings (Smith et al., 2010). Although more collaborative research in marketing and neuroscience is needed to confirm these findings, the data can serve as a catalyst for a potential explanation about why affect intensity may at times be associated with food cravings.

We found that high affect intensity individuals relied more on their emotions than their self-regulatory resources (Study 1), and this impulse control failure was associated with higher craving intensity, and ultimately, more behavioral intentions. This finding makes three contributions to the extant literature. First, despite the plethora of research on personality traits associated with impulse control and impulse buying (Rook \& Gardner, 1993; Verplanken \& Herabadi, 2001), this is one of the first studies to link impulse control failure with affect intensity (Tice et al., 2001). People who are dispositionally inclined to experience their emotions more intensely are the same ones who have difficulty controlling their appetitive impulses. Second, the findings are consistent with self-regulation theory which asserts that emotional stimulation magnifies the salience of emotionally evocative objects, and shifts the perceiver's attention to the immediate moment rather than the pursuit of distal goals (Baumeister \& Heatherton, 1996). Additional research is warranted to gain a deeper understanding of the characteristics and mindsets of consumers who surrender to their cravings for palatable, but unhealthy foods (Hofmann et al., 2009). Third, researchers have demonstrated that negative emotion undermines self-regulation (Tice et al., 2001), while positive mood (e.g. induced by humor) can boost impulse control and improve self-regulation (Tice, Baumeister, Shmueli, \&
Muraven, 2007). In contrast, we have shown that a positive situation (i.e. anticipating the pleasure of palatable food) did just the opposite; it was associated with weakened impulse control among high affect intensity individuals, especially those high in the positive affectivity subscale. Future research should examine whether positive emotion is associated with poor impulse control in other consumer behavior domains.

Another contribution of this investigation is the discovery that high affect intensity people experience elevated pleasure anticipation, which amplifies food cravings. One possible reason is that although sensory cues in advertising appeals can enhance pleasure and taste perception (Elder \& Krishna, 2010), it may not be food cues themselves that unleash the appetitive motivation. Rather, it may be the unique manner in which the perceiver's brain amplifies hedonic hotspots to transform stimuli into liked and desired objects of pleasure (Berridge et al., 2010; Smith et al., 2010). In order for a person to develop appetitive desire for a specific substance, an interconnected neural network of 'hedonic hotspots' must spring into action to cause the object of interest to be perceived as something pleasurable (Berridge et al., 2010; Pecina et al., 2006; Smith et al., 2010). This interactive process, coordinated by hedonic hotspots, may magnify sensory pleasure, which in turn may increase salivation for the target food (Pecina et al., 2006). One implication is that it is therefore quite possible that high affect intensity individuals respond to hedonic stimuli in a way that activates more hedonic hotspots in key brain regions, which in turn amplifies the anticipation of pleasure and craving impulses. Future research in marketing should therefore collaborate with affective neuroscientists to determine whether high affect intensity individuals would experience stronger activations in the reward centers of the brain when exposed to vivid food advertisements.

Moderators of the relationship between affect intensity and consumption-related responses.

In Studies 3 and 4 we examined the joint roles of individual differences (i.e. affect intensity, dieting status) and contextual features (e.g. features of advertisements) in predicting consumption-related outcomes. The results in Study 3 indicate for the first time that vivid advertisements have different effects on people depending on their levels of affect intensity: high affect intensity people are especially susceptible to such ads. In Study 4, the vivid version of the pizza was represented by its full color that magnified the enticing richness of the mozzarella cheese and the other toppings (e.g. red peppers). Therefore, the presence of color presumably activated the hot emotional system (Metcalfe \& Mischel, 1999). These findings expand the significance of recent work finding that brightness of ambient light turned on the hot emotional system and intensified people's initial affective response; this, in turn influenced the respondent's judgments as well as the desire to eat spicier foods (Xu \& Labroo, 2014)

Moreover, in Study 4, dieting also seems to amplify the responses of high affect intensity people to vivid cues, literally making these cues more mouthwatering. Dieters who were both high in affect intensity and exposed to a vivid food advertisement, salivated more than dieters who saw a pallid 
advertisement, even though the two ads only differed by a single feature (i.e. color versus black-and-white). These findings are consistent with previous research which shows that restrained dieters are associated with heightened salivary responsiveness to food stimuli (Brunstrom et al., 2004; LeGoff \& Spigelman, 1987).

This study is among the first to find that positive affectivity is the only sub-factor of affect intensity that is a significant predictor of craving intensity and salivation response (Table 1). Two important implications of this finding should be noted. First, given the inconsistent literature on the relationship between exposure to food stimuli and salivation responses (Krishna et al., 2014; Spence, 2011), this study has shown that there may be other unmeasured variables (like personality traits) that could be used to predict salivation responses. This underscores the importance of taking into consideration the role of such variables, rather than assuming that all respondents are homogeneous in their appetitive response to sensory stimuli. Second, since positive affectivity was the only sub-dimension of the affect intensity construct to predict salivation responses, this supports the recommendation that when personality constructs are multidimensional like the affect intensity scale, the use of specific sub-dimensions of the scale may be more interpretable and less misleading than the use of the total scale (Bagozzi, 1994).

These results also demonstrate that increased salivation may not necessarily lead to increased desires to eat food. Rather, exposure to food temptations that exceed a certain critical level can activate inhibitory strategies that may motivate restrained eaters (dieters) to control their consumption (Fishbach et al., 2003). Dieters tend to use cognitive suppression to control food intake (Nederkoorn \& Jansen, 2002), and dieters who were high in positive affectivity may have been especially good at suppressing their appetitive urges, presumably to cope with the eating temptation (Nederkoorn \& Jansen, 2002). This is a plausible explanation of the finding that positive affectivity was associated with an increased desire to eat unhealthy food only among non-dieters, who are less motivated to suppress their appetitive urges. Future research is needed to clarify the conditions under which high positive affectivity restrained eaters suppress their appetitive urges in light of recent neuroscience research indicating that when sensory pleasures are stimulated by exposure to food, this can activate a very powerful "go" system in the human brain that is difficult to 'turn off' and can lead to uncontrolled overeating (Berridge et al., 2010). In other words, the unanswered question that remains is: if exposure to appetizing food can trigger overeating, why does this only seem to apply to non-dieters high in positive affectivity? We think that one potential explanation for the high positive affectivity dieters' seeming restraint in the face of increased salivation is that they were working hard at inhibiting this "go" system. Whether these processes are conscious (i.e. respondents want to look good) or non-conscious (i.e. automatic suppression) is a question for future research. But we suspect that such suppression is likely to take its toll on the high positive affectivity dieters - which is another empirical question.

\section{Marketing implications, future directions, and conclusion}

People scoring high on affect intensity enjoy consuming a number of emotionally-evocative media such as movies and television shows with drama, romance, and excitement (e.g. soap operas, major sports events, romantic dramas in movies; Moore \& Homer, 2000). Therefore, because of their predictable media preferences, high affect intensity people can be targeted by media strategists. Based on this prior research and on the results of the current paper, marketers might selectively choose to place more vivid and sensory-focused ads in these more emotionally evocative types of media to target this consumer segment. At the same time, they could more accurately target the appropriate audience if they reserve their more pallid ads, which seem to be more effective for low affect intensity people, to less emotionally evocative media types (e.g. newspapers, newsmagazines, some talk radio shows). Taken together, we find that both vivid and pallid advertisements have their place, but they have to be matched to the consumer trait and their preferred type of media consumption. Policy-makers might also be interested in targeting vivid and evocative ads (e.g. fear appeal images commonly used in anti-smoking campaigns) versus more pallid and informationfocused ones (e.g. statistics about potential effects of smoking) to the correct type of media (Bagozzi \& Moore, 1994).

Research has also found that high affect intensity people are quite sociable, strongly preferring to participate in stimulating social activities that take them outside of the house (e.g. going to parties with friends, dancing, eating at restaurants with friends). They are less interested in solo outside activities (e.g. biking or jogging alone) or quiet indoor activities (Moore \& Homer, 2000). Thus, future research should examine the role of another external cue that was not tested in the current paper: the social versus non- social nature of ads. Ads containing more social information (e.g. people enjoying a product together) are likely to be more effective for high affect intensity people, while those containing less social information (e.g. an individual enjoying a product alone) are likely to be more effective for low affect intensity individuals. Again, these specific ad types should also perhaps be targeted to the correct type of media (e.g. more social ads in more emotionally evocative programs).

Advertisers and marketing strategists may also benefit from the fact that people who manifest intense positive emotions also experience elevated pleasure anticipation (Elder \& Krishna, 2010). One exciting possibility is that consumers with high positive affectivity may also be equipped with a greater capacity to engage in savoring - a process whereby people willingly believe in their ability to derive pleasure through anticipating upcoming positive events (Bryant, 2003). It may be quite feasible to assume that high positive affectivity consumers are also capable of savoring with sustained interest a future event that offers the promise of pleasurable consumption experience such as a delightful vacation or an exciting sporting event. Very often, for example, consumers purchase tickets for an event that may occur many months later (like the World Cup Soccer final playoff). Because of this long delay before consumption occurs (Nowlis, Mandel, \& McCabe, 2004), purchasing tickets a long time in advance presumably calls for a special ability to anticipate and 
savor the pleasures of consumption (Bryant, 2003). High positive affectivity consumers may be more motivated to sustain their interest in events where consumption is delayed. Since maintaining a sustained level of anticipation and savoring can conceivably reduce the motivation to cancel bookings and reservations for future pleasurable events, advertisers should design their communications to bolster and encourage the savoring process.

Some limitations of the current studies must be considered. First, Studies 1 and 2 were cross-sectional, making it difficult to determine the direction of causality and the role of potential third variables. Future studies should causally manipulate variables that might interact with affect intensity to increase food cravings. For example, available impulse control resources could be manipulated via cognitive load (versus control) tasks (e.g. Ward \& Mann, 2000). High affect intensity individuals should be less able to resist their food cravings after completing difficult cognitive tasks. Second, future studies should extend this work into more diverse adult populations, rather than exclusively relying on undergraduates as we did.

Overall, our main contribution may well be the creation and initial testing of a general theoretical model that we hope stimulates much future research (Fig. 1). In the current paper, we aimed to develop an overarching explanatory framework that could generate useful ideas and hypotheses, and ultimately, fruitful future research in the area of sensory marketing (Krishna, 2012) and food consumption research. We hope that this person by situation theoretical framework (Anderson \& Bushman, 2002) inspires many future studies in a variety of consumer domains.

\section{Appendix A}

\section{Study 1 stimulus: vivid description}

\section{Cinnabon ${ }^{\circledR}$ rolls}

You are out shopping and now you are now quite hungry. Almost suddenly you run into a corner store where a few hungry people are waiting in line for freshly baked Cinnabon ${ }^{\circledR}$ rolls. Joining the line, you glance forward toward the oven and catch a glimpse of the golden pastry with a rich Cinnabon ${ }^{\circledR}$ swirl, a delicate glaze melting over the warm and gooey spirals of dough. As you make your purchase, a fresh batch of Cinnabon ${ }^{\circledR}$ rolls is taken out of the oven. Soon the Cinnabon ${ }^{\circledR}$ rolls are in your hand and with your bare fingers you break your first roll in half; it warms your soul as you prepare yourself for an experience you'll never forget.

\section{Study 2 stimulus: vivid description}

Pizza

You and a friend are shopping at the mall and now you have become quite hungry. You decide to have lunch at a dine-in pizza restaurant. Because you are ravenously hungry, you quickly examine the menu and order the best tasting pizza. Minutes later the pizza arrives at your table; the smell is heavenly. The warm delicious aroma hits you in the face. The crust is flaky and golden brown outside, warm and chewy on the inside. The cheese melts in abundance all over the pizza crust. It is gooey and looks really appetizing. Delicious toppings are spread over the pizza. Excitedly you reach for the first slice and begin to devour. You sink your teeth into a thick juicy slice.

\section{Study 3 stimuli}

Product description: vivid, pleasure-focused version (cookies)

You and a friend are shopping at the mall and now you have become quite hungry. Almost suddenly, you run into a small storefront where a few eager people are waiting in line for freshly baked cookies. As you join the line you could actually see a batch of your favorite cookies baking in the oven close by. You are almost completely overpowered by the sight of those delicious cookies. Soon the timer goes off and the attendant pulls the cookies out of the oven. You see that they are perfectly done, nice and golden-brown on the outside. By now you are dying to have a cookie. Charmed by this experience, you place your order and soon you and your companion walk away with your order.

Product description: pallid, information-focused version (cookies)

You and a friend are shopping at the mall and now you have become quite hungry. Suddenly, you find yourself close to a small storefront where a few eager people are waiting in line. As you join the line you could actually see that the store is considerate enough to list the ingredients and nutritional values associated with each of its products. The type of cookie you are interested in contains 160 calories, $3 \mathrm{~g}$ of saturated fat, $10 \mathrm{~g}$ of sugar and 3\% fiber. The sodium content is $280 \mathrm{mg}$ while the potassium level is $30 \mathrm{mg}$. Armed with this nutritional information, you place your order and soon you and your companion walk away with your order.

\section{Product description: vivid, pleasure-focused version (pizza)}

You and a friend are shopping at the mall and now you have become quite hungry. You decide to have lunch at a dine-in pizza restaurant. Because you are ravenously hungry, you quickly examine the menu and order the best tasting pizza. Minutes later the pizza arrives at your table; the smell is heavenly. The warm delicious aroma hits you in the face. The crust is flaky and golden brown outside, warm and chewy on the inside. The cheese melts in abundance all over the pizza crust. It is gooey and looks really appetizing. Delicious toppings are spread over the pizza. Excitedly you reach for the first slice and begin to devour. You sink your teeth into a thick juicy slice.

Product description: pallid, information-focused version (pizza)

You and a friend are shopping at the mall and now you have become quite hungry. You decide to have lunch at a dine-in pizza restaurant. Having been seated comfortably, you examine the menu and place your order. You observe that the nutritional information is provided for all the various types of pizzas on the menu list. For example, a regular pan pizza contains 722 calories, $33 \mathrm{~g}$ of protein, $70 \mathrm{~g}$ of carbohydrates and $12 \mathrm{~g}$ of saturated fat. 
The actual amount of cholesterol present in each pizza is $66 \mathrm{mg}$, while the number of calories derived from fat is $66 \%$. As the pizza arrives you reach for the first slice and you begin to eat.

\section{Study 4 stimuli}
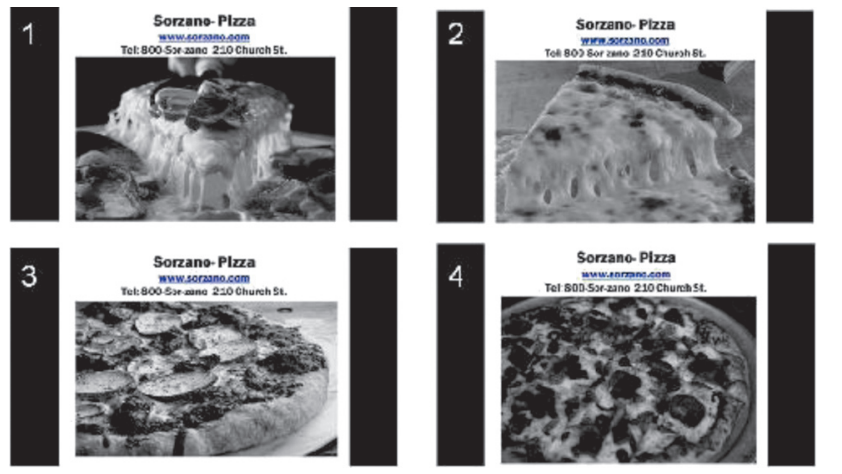

Picture 1a) Pallid pizza images
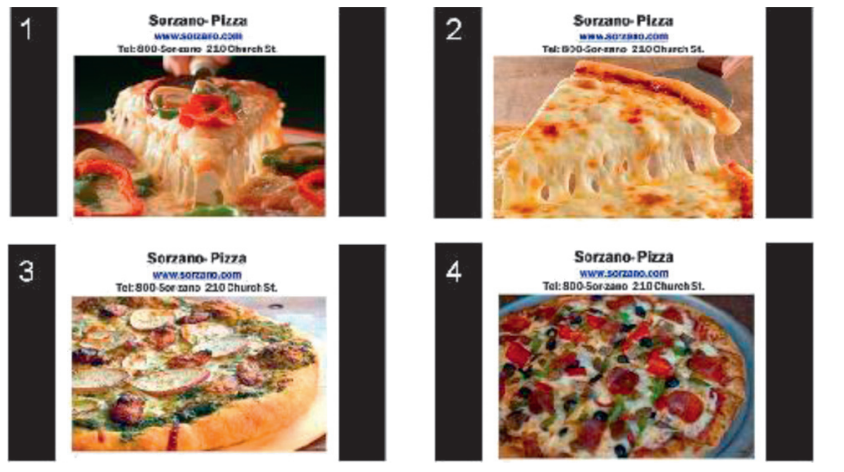

Picture 1b) Vivid pizza images

\section{References}

Alba, W., \& Williams, E. F. (2013). Pleasure principles: A review of research on hedonic consumption. Journal of Consumer Psychology, 23(1), 2-18.

Anand-Keller, P., \& Block, L. (1997). Vividness effects: A resource-matching perspective. Journal of Consumer Research, 24, 295-304.

Anderson, C. A., \& Bushman, B. J. (2002). Human aggression. Annual Review of Psychology, 53(1), 27-51.

Bagozzi, R. P. (1992). The self-regulation of attitudes, intentions, and behavior. Social Psychology Quarterly, 55, 178-204.

Bagozzi, Richard P. (1994). ACR fellow speech. In Chris T. Allen, \& Deborah R. John (Eds.), Advances in consumer research. , 21. (pp. 8-11). Association for Consumer Research.

Bagozzi, R. P., \& Moore, D. J. (1994). Public service advertisements: Emotions and empathy guide pro-social behavior. Journal of Marketing, 58(1), $56-70$.

Bagozzi, R. P., \& Moore, D. J. (2011). On the dimensionality and construct validity of the affect intensity measure. Journal of Testing, Psychometrics, and Methodology in Applied Psychology, 18, 3-18.

Baumeister, R. F. (2002). Yielding to temptation: Self-control failure, impulsive purchasing, and consumer behavior. Journal of Consumer Research, 28, 670-676.

Baumeister, R. F., \& Heatherton, T. F. (1996). Self-regulation failure: An overview. Psychological Inquiry, 7, 1-15.
Belk, R. W., Ger, G., \& Askegaard, S. (2003). The fire of desire: A multisited inquiry into consumer passion. Journal of Consumer Research, 30, 326-351.

Berridge, K. C., Ho, C. -Y., Richard, J. M., \& DiFeliceantonio, A. G. (2010). The tempted brain eats: Pleasure and desire circuits in obesity and eating disorders. Appetite, 1350, 43-64.

Bonans, S. R., \& Noble, A. C. (1995). Interaction of salivary flow with temporal perception of sweetness, sourness, and fruitiness. Physiology and Behavior, 57, 569-574.

Brunstrom, J. M., Yates, H. M., \& Witcomb, G. L. (2004). Dietary restraint and heightened reactivity to food. Physiology \& Behavior, 81, 85-90.

Bryant, F. B. (2003). Savoring beliefs inventory (SBI): A scale for measuring beliefs about savoring. Journal of Mental Health, 12(2), 175-196.

Bryant, F. B., Yarnold, P. R., \& Grimm, L. G. (1996). Toward a measurement model of the affect intensity measure: A 3-factor structure. Journal of Research in Personality, 30, 223-247.

Canetti, L., Bachar, E., \& Berry, E. (2002). Food and emotion. Behavioral Processes, 60, 157-164.

Cepeda-Benito, A., Gleaves, D., Williams, T., \& Erath, S. (2000). Development and validation of the state and trait food-cravings questionnaire. Behavior Therapy, 31, 151-173.

Cooper, M. L. (2010). Toward a person $\times$ situation model of sexual risk-taking behaviors: Illuminating the conditional effects of traits across sexual situations and relationship contexts. Journal of Personality and Social Psychology, 98(2), 319.

Cropanzano, R., Weiss, H. M., Hale, J. M. S., \& Reb, J. (2003). The structure of affect. Reconsidering the relationship between negative and positive affectivity. Journal of Management, 29(6), 831-857.

Edell, J. A., \& Burke, M. C. (1987). The power of feelings in understanding advertising effects. Journal of Consumer Research, 14, 421-433.

Elder, R. S., \& Krishna, A. (2010). The effects of advertising copy on sensory thoughts and perceived taste. Journal of Consumer Research, 36, 748-756.

Escalas, J. (2004). Narrative processing: Building consumer connections to brands. Journal of Consumer Psychology, 14, 168-180.

Fedorikhin, A., \& Patrick, V. M. (2010). Positive mood and resistance to temptation: The interfering influence of elevated arousal. Journal of Consumer Research, 37, 698-711.

Fedoroff, I. D. C., Polivy, J., \& Herman, C. P. (1997). The effect of preexposure to food cues on the eating behavior of restrained and unrestrained eaters. Appetite, 28(1), 33-47.

Fedoroff, I., Polivy, J., \& Herman, C. P. (2003). The specificity of restrained versus unrestrained eaters' responses to food cues: General desire to eat, or craving for the cued food? Appetite, 41, 7-13.

Fishbach, A., Friedman, R. S., \& Kruglanski, A. W. (2003). Lead us not into temptation: Momentary allurements elicit overriding goal activation. Journal of Personality and Social Psychology, 84, 296-309.

Gard, D. E., Gard, M. G., Kring, A. M., \& John, O. P. (2006). Anticipatory and consummatory components of the experience of pleasure: A scale development study. Journal of Research in Personality, 40, 1086-1102.

Gardner, M. P., Wansink, B., Kim, J., \& Park, S. (2014). Better moods for better eating? How mood influences food choice. Journal of Consumer Psychology, 24(3), 320-335.

Garg, N., Wansink, B., \& Inman, J. J. (2007). The influence of incidental affect on consumers' food intake. Journal of Marketing, 71, 194-206.

Geyskens, K., Dewitte, S., Pandelaere, M., \& Warlop, L. (2008). Tempt me just a little bit more: The effect of food temptation actionability on goal activation and consumption. Journal of Consumer Research, 35, 600-610.

Gross, J. L., \& Levenson, R. L. (1993). Emotional suppression: Physiology, self-report, and expressive behavior. Journal of Personality and Social Psychology, 64, 970-986.

Hamann, S. (2001). Cognitive and neural mechanisms of emotional memory. Trends in Cognitive Sciences, 5, 394-399.

Hill, A. (2007). The psychology of craving. Proceedings of the Nutritional Society, 66, 277-285.

Hoch, S. J., \& Loewenstein, G. F. (1991). Time-inconsistent preferences and consumer self-control. Journal of Consumer Research, 17, 492-507.

Hofmann, W., Friese, M., \& Strack, F. (2009). Impulse and self-control from a dual-systems perspective. Perspectives on Psychological Science, 4, $162-176$. 
Ilangakoon, Y., \& Carpenter, G. H. (2011). Is the mouthwatering sensation a true salivary reflex? Journal of Texture Studies, 42(3), 212-216.

Kergoat, M., Giboreau, A., Nicod, H., Faye, P., Diaz, E., Beetschen, M., et al. (2012). Consumer preference for tactile softness: A question of affect intensity? Journal of Sensory Studies, 27, 232-246.

Klajner, F., Herman, C. P., Polivy, J., \& Chhabra, R. (2000). Human obesity, dieting, and anticipatory salivation to food. Physiology \& Behavior, 27(2), 195-198.

Krishna, A. (2012). An integrative review of sensory marketing: Engaging the senses to affect perception, judgment, and behavior. Journal of Consumer Psychology, 22, 332-351.

Krishna, A., Morrin, M., \& Sayin, E. (2014). Smellizing cookies and salivating: A focus on olfactory imagery. Journal of Consumer Research, 41(1), 18-34.

Krishna, A., \& Schwarz, N. (2014). Sensing marketing, embodiment, and grounded cognition: A review and introduction. Journal of Consumer Psychology, 24, 159-168

Larsen, R. J., Billings, D., \& Cutler, S. (1996). Affect intensity and individual differences in informational style. Journal of Personality, 64, 185-208.

Larsen, R. J., \& Diener, E. (1987). Affect intensity as an individual difference characteristic: A review. Journal of Research in Personality, 21, 1-39.

Larsen, R., Diener, E., \& Cropanzano, R. (1987). Cognitive operations associated with individual differences in affect intensity. Journal of Personality and Social Psychology, 33, 767-774.

LeGoff, D. B., \& Spigelman, M. N. (1987). Salivary response to olfactory food stimuli as a function of dietary restraint and body weight. Appetite, 8 , $29-35$.

Loewenstein, G. (1996). Out of control: Visceral influences on behavior. Organizational Behavior and Human Decision Process, 65, 272-292.

Loewenstein, G., \& O’Donoghue, T. (2007). The heat of the moment: Modeling interactions between affect and deliberation. Working Paper. Carnegie Mellon University.

Lowe, M. R., \& Butryn, M. L. (2007). Hedonic hunger: A new dimension of appetite? Physiology \& Behavior, 91, 432-439.

Lowe, M., Butryn, M., Didie, E., Annunziato, R., Thomas, J., Crerand, C., et al. (2009). The power of food scale. A new measure of the psychological influence of the food environment. Appetite, 53, 114-118.

Metcalfe, J., \& Mischel, W. (1999). A hot/cool-system analysis of delay of gratification: Dynamics of willpower. Psychological Review, 106, 3-19.

Moore, D. J. (2014). Is anticipation delicious? Visceral factors as mediators of the effect of olfactory cues on purchase intentions. Journal of Business Research, 67, 2014-2051.

Moore, D. J., Harris, W. D., \& Chen, H. C. (1995). Affect intensity: An individual difference response to advertising appeals. Journal of Consumer Research, 22, 154-164.

Moore, D. J., \& Homer, P. M. (2000). Dimensions of consumer temperament: Affect intensity and consumer lifestyles. Journal of Consumer Psychology, 9(4), 231-242.

Nederkoorn, C., \& Jansen, A. (2002). Cue reactivity and regulation of food intake. Eating Behaviors, 3, 61-72.

Nederkoorn, C., Smulders, F. T. Y., \& Jansen, A. (2000). Cephalic phase responses, craving and food intake in normal subjects. Appetite, 35, 45-55.

Nowlis, S. N., Mandel, N., \& McCabe, D. B. (December, 2004). The effect of a delay between choice and consumption on consumption enjoyment. Journal of Consumer Research, 13, 502-510.

O’Doherty, J. P., Deichmann, R., Critchley, H. D., \& Dolan, R. J. (2002). Neural responses during anticipation of a primary taste reward. Neuron, 33, 815-826.
Pangborn, R. M., \& Berggren, B. (1973). Human parotid secretion in response to pleasant and unpleasant odorants. Psychophysiology, 10(3), 231-237.

Pecina, S., Smith, K. S., \& Berridge, K. C. (2006). Hedonic hot spots in the brain. The Neuroscientist, 12, 500-511.

Pelchat, M. L., Johnson, A., Chan, R., Valdez, J., \& Ragland, J. D. (2004) Images of desire: Food-craving activation during fMRI. NeuroImage, 23, 1486-1493.

Preacher, K. J., \& Hayes, A. F. (2004). SPSS and SAS procedures for estimating indirect effects in simple mediation models. Behavior Research Methods, Instruments, \& Computers, 36(4), 717-731.

Preacher, K. J., \& Hayes, A. F. (2008). Indirect: SPSS macro for multiple mediation.

Rogers, P. J., \& Hill, A. J. (1989). Breakdown of dietary restraint following mere exposure to food stimuli: Interrelationships between restraint, hunger, salivation, and food intake. Addictive Behaviors, 14, 387-397.

Rook, D. W. (1987). The buying impulse. Journal of Consumer Research, 14(2), 189-199.

Rook, D. W., \& Gardner, M. P. (1993). In the mood: Impulse buying's affective antecedents. Research in Consumer BehaviorGreenwich, CT: JAI Press.

Scott, M. L., Nowlis, S. M., Mandel, N., \& Morales, A. C. (2008). The effects of reduced food size and package size on the consumption behavior of restrained and unrestrained eaters. Journal of Consumer Research, 35, 391-405.

Shiv, B., \& Fedorikhin, A. (2002). Spontaneous versus controlled influences of stimulus-based affect on choice behavior. Organizational Behavior and Human Decision Processes, 87, 342-370.

Siwik, V. P., \& Senf, J. H. (2006). Food cravings, ethnicity and other factors related to eating out. Journal of the American College of Nutrition, 25, 382-388.

Smith, K. S., Mahler, S. V., Pecina, S., \& Berridge, K. C. (2010). Hedonic hotspots: Generating sensory pleasure in the brain. In M. L. Kringelbach, \& K. C. Berridge (Eds.), Pleasures of the brain (pp. 27-49). Oxford, U.K: Oxford University Press.

Spence, C. (2011). Mouth-watering: The influence of environmental and cognitive factors on salivation and gustatory/flavor perception. Journal of Texture Studies, 42, 157-171.

Stipp, D. (2011, June). Obesity, not aging, balloons health care costs, MillerMcCune Magazine.

Tice, D. M., Baumeister, R. F., Shmueli, D., \& Muraven, M. (2007). Restoring the self: Positive affect helps improve self-regulation following ego depletion. Journal of Experimental Social Psychology, 43, 379-384.

Tice, D. M., Bratslavsky, E., \& Baumeister, R. F. (2001). Emotional distress regulation takes precedence over impulse control: If you feel bad, do it! Journal of Personality and Social Psychology, 80, 53-67.

Verplanken, B., \& Herabadi, A. (2001). Individual differences in impulse buying tendency: Feeling and no thinking. European Journal of Personality, 15, S71-S83.

Ward, A., \& Mann, T. (2000). Don't mind if I do: Disinhibited eating under cognitive load. Journal of Personality and Social Psychology, 78, 753-763.

Winsor, A. L. (1930). The effect of dehydration on parotid secretion. The American Journal of Psychology, 602-607.

Xu, A. J., \& Labroo, A. A. (2014). Incandescent affect: Turning on the hot emotional system with bright lights. Journal of Consumer Psychology, 24(2), 207-216.

Zuckerman, M. (1979). Sensation seeking. Beyond the optimal level of arousal. Hillsdale, N.J: Lawrence Erlbaum. 